\title{
Mapeamento geoecológico da susceptibilidade à ocorrência de incêndios do Parque Estadual da Serra da Concórdia - Valença RJ
}

\author{
Geoecological Mapping of Fire Susceptibility in Serra da Concórdia State Park - Valença RJ \\ Shirlei Cardoso Andrade ${ }^{\dagger}$, Alex Franco Ferreira ${ }^{t^{*}}$
}

Como citar esse artigo. Andrade,

SC; Ferreira, AF. Mapeamento

Geoecológico Da Susceptibilidade À Ocorrência De Incêndios No Parque Estadual da Serra da Concórdia - Valença RJ. Revista Teccen. 2019 Jul./Dez.; 12 (2): 45-58.

\begin{abstract}
Resumo
O estudo foi desenvolvido na área do Parque Estadual da Serra da Concórdia, localizado no município de Valença, Estado do Rio de Janeiro, com uma área total de aproximadamente 804,41ha de vegetação predominante do Bioma Mata Atlântica. Este estudo objetivou mostrar que se aplicando as tecnologias de Geoprocessamento tais como: Sistema de Informação Geográfica (SIG), Sensoriamento Remoto, aliado à metodologia analítico-integrativa desenvolvida em pesquisas de Coelho Netto et al (2007),é possível elaborar mapas de susceptibilidade à ocorrência de incêndios florestais, que podem contribuir para a prevenção e controle de focos de incêndios na área do Parque, já que os focos de incêndios vêm sendo uma das principais causas de degradação dos espaços florestais. Foram utilizados Modelo Digital de Elevação (MDE), Imagens do sensor Ikonos, dados do sensor Modis e Mapa de Uso e Cobertura do Solo para a elaboração e validação dos Mapas de Forma de Encosta, Orientação, Radiação Solar Anual, Combustibilidade e Susceptibilidade à Ocorrência de Incêndios. Para validação da metodologia analítico-integrativa com utilização forma das encostas, orientação das encostas, total de radiação solar e uso e cobertura do soloempregaram-se os dados de focos de calor anual, detectados pelo sensor Modis e disponibilizados pelo Instituto Nacional e Pesquisas Espaciais (INPE) na área. Estes focos de calor foram espacializados sobre os mapas elaborados, mostrando resultados bastante promissores em relação à eficiência da metodologia.

Palavras-Chave: Sistema de Informação Geográfica (SIG), Serra da Concórdia; Incêndios, Mapa de Susceptibilidade.
\end{abstract}

\begin{abstract}
The study was carried out at Parque Estadual da Serra da Concórdia, in Valença, in the Rio de Janeiro state, with a total area of approximately 804.41 hectares of vegetation predominant of the Atlantic Forest Biome. This study aimed to show that by applying the technologies such as GIS: Geographic Information System (GIS), remote sensing, combined with the integrative analytical methodology developed by Coelho Netto et al (2007), it makes it possible to map the susceptibility of forest fires, which may contribute to the prevention and control of outbreaks of fires in the Park, since the outbreak of fires has been a major cause of degradation of forest areas. In this study, we used digital elevation model (DEM), Images from the Ikonos sensor, MODIS sensor data and Map of Use and Land Cover for the development and validation of maps of Slope Shape, Orientation, Annual Solar Radiation, Combustibility and Susceptibility to the occurrence of fires. To validate the analytical-integrative methodology with the use of slope form, slope orientation, total solar radiation and use and ground cover, annual heat spot data used in the study, we used data from annual hotspots detected by MODIS and made available by Instituto Nacional e Pesquisas Espaciais (INPE) about the area. These hotspots werespatialized on the elaborated maps, showing very promising results regarding the efficiency of the methodology.

Keywords: GeographicInformation System (GIS), Serra da Concórdia,Fires;Susceptibility Map.
\end{abstract}

\section{Introdução}

A questão ambiental é atualmente discutida em todas as áreas do conhecimento, o que levou vários segmentos da sociedade a intensificar esforços voltados à conservação do meio ambiente. $\mathrm{O}$ homem é personagem importante nesta questão, já que é capaz de intervir significativamente no meio ambiente e produzir grandes transformações no espaço físico.

Dentre as áreas antropicamente mais afetadas no Brasil encontra-se a Mata Atlântica, pois abriga extensa diversidade biológica, inúmeras comunidades tradicionais, um rico patrimônio cultural e assegura a proteção dos solos, sítios turísticos e mananciais, sendo reconhecida pela UNESCO como Reserva da Biosfera.

De acordo com Câmara (2001), a manutenção desse importante sistema, depende da preservação de seus remanescentes e de ações de manejo e recuperação. As florestas mantêm nascentes e fontes, regulando o fluxo dos mananciais d'água. Porém, em função das poucas áreas que restam de florestas primárias na Mata Atlântica, as florestas secundárias exercem hoje algumas funções ou serviços ambientais cruciais no equilíbrio do clima, no sequestro de carbono, na preservação do solo, dos mananciais de água, no controle de pragas e doenças na agricultura e na sobrevivência das muitas

Afiliação dos autores: † Universidade de Vassouras, Vassouras, RJ, Brasil

\$Pró-Reitoria de Pesquisa e Pós-Graduação, Universidade de Vassouras, Vassouras, RJ, Brasil

* Email para correspondência: alexfferreira@gmail.com 
espécies da flora e da fauna. Sendo assim, as Unidades de Conservação brasileiras são espaços territoriais protegidos, bem como seus recursos ambientais, legalmente instituídas pelo Poder Público. Isto posto, as unidades de conservação de uso indireto possuem uma zona de amortecimento, que tem a finalidade de minimizar os impactos negativos sobre a mesma.

O Parque Estadual da Serra da Concórdia (UCEI - Ministério do Meio Ambiente), parte do domínio da Mata Atlântica, localizado no município de Valença/ RJ, suporta diferentes formas de ocupação e manejo de seus recursos naturais, constituindo-se num ambiente de grande interesse para estudos ambientais.

Os incêndios fazem parte da temática dos desastres naturais que ocorrem nas escalas local e regional, e podem ser provocados pelo homem por meio intencional ou acidentalmente.

Os efeitos dos incêndios florestais sobre $\mathrm{o}$ ecossistema acarretam a destruição da cobertura vegetal e da fauna, implicando além da debilitação de árvores jovens suscetíveis a pragas e doenças; a perda de nutrientes e ressecamento do solo, aceleração do processo de erosão; assoreamento de rios, lagos e lagoas.

Para Fernandes (1998) no contexto de incêndio florestal,omapeamento geoecológico dasusceptibilidade a incêndios observa os aspectos geomorfológicos e antrópicos que são primordiais para o refinamento do estudo, em vista de serem mais ou menos propícios aos incêndios florestais de acordo com a influência que estes exercem sobre uma determinada região.

Este trabalho teve como objetivo principal elaborar o mapeamento geoecológico da susceptibilidade à ocorrência de incêndios, utilizando as ferramentas de geoprocessamento e conceitos geoecológicos para a paisagem do Parque Estadual da Serra da Concórdia. E, como objetivo específico, construir a partir da metodologia um mapa de susceptibilidade à ocorrência de incêndios, durante operíodo anual de 2011 para o Parque Estadual da Serra da Concórdia.

O presente estudo é oriundo de uma experiência realizada por Fernandes (1998) no maciço da Tijuca e posteriormente aperfeiçoada por Souza (2009) no maciço da Pedra Branca. Trata-se de uma unidade geomorfológica, que juntamente com o maciço da Tijuca e o Gericinó-Mendanha constituem o compartimento de maciços litorâneos da cidade do Rio de Janeiro.

Sendo assim, este trabalho utiliza novas tecnologias como as imagens de satélite, que são produto do sensoriamento remoto e são muito uteis para descrever os usos do solo e sua relação com os meios físicos e bióticos bem como a partir a dos mapas elaborados podem ser fornecidos instrumentos de auxílio à elaboração de estratégias de combate aos incêndios florestais no Parque Estadual da Serra da Concordia, que conforme demonstrado, apresenta áreas susceptíveis a ocorrência de incêndios.

\section{Materiais e Métodos}

Nesta proposta, a metodologia adotada é baseada na integração dos vários aspectos cartográficos e ambientais, assim como informações relacionadas a dinâmica que envolvem a susceptibilidade à ocorrência de incêndios.

É importante salientar que entre as restrições deste estudo, está a detecção das fontes de calor por imagens de satélite obtidas do INPE, poisos sensores a bordo dos satélites possuem limitações que devem ser conhecidas para se evitar generalizações que podem comprometer o monitoramento e a elaboração dos mapas de avaliação de uma determinada região.

A detecção de focos de calor por imagens de satélite tem uma série de limitações que precisam ser compreendidas para a sua correta utilização. O elemento de resolução espacial (pixel) dos satélites em órbita polar tem $1 \mathrm{~km} \times 1 \mathrm{~km}$ ou mais, portanto uma queimada de algumas dezenas de metros quadrados será registrada como tendo pelo menos $1 \mathrm{~km}^{2}$ ou, no caso dos satélites geoestacionários, $16 \mathrm{~km}^{2}$. (Setzer et al. 2010)

INPE (2011) informa que a imprecisão na localização dos focos de calor é de cerca de $1 \mathrm{~km}$, podendo chegar a $6 \mathrm{~km}$. Trabalhos de validação de campo indicam que frentes de fogo com cerca de $30 \mathrm{~m}$ de extensão por $1 \mathrm{~m}$ de largura podem ser detectadas pelos satélites, porém diversos fatores podem impedir ou prejudicar a detecção dos focos, como:

- Queimadas de pequena duração, ocorrendo entre as imagens disponíveis;

- Fogo em uma das encostas de determinada montanha, enquanto que o satélite sóobservou o outro lado;

- Nuvens cobrindo a região na hora do imageamento;

- Fogo apenas no chão de uma floresta densa (INPE 2011).

Os dados foram obtidos nas imagens termais dos satélites meteorológicos NOAA quatro vezes ao dia, GOES oito vezes ao dia, e Terra e Aqua duas vezes por dia, e em seguida integrados a dois sistemas geográficos de informações (SpringWeb-Queimadas e TerraLibQueimadas) que podem ser utilizados pela Internet. As informações são disponibilizadas operacionalmente aos usuários cerca de 20 minutos após as passagens dos satélites. Todo o País e grande parte da América do Sul são cobertos pelas imagens, pois utiliza-se recepções das estações do INPE em Cachoeira Paulista, SP e de Cuiabá, MT. (CPTEC/INPE, 2004)

Um dos sensores a bordo dos satélites é o MODIS 
- com 36 bandas espectrais e uma resolução radiométrica de 12 bits. Este sensor possui um maior número de bandas espectrais que os outros imageadores de baixa - média resolução espacial já lançados anteriormente. (CPTEC/INPE, 2004)

Segundo INPE (2011), as bandas do MODIS para o estudo da superfície terrestre (landbands) possuem resolução espacial de $250 \mathrm{~m}$ (para os canais do vermelho e infravermelho próximo) e $500 \mathrm{~m}$ (para a banda do azul). As duas primeiras fornecem informações sobre cobertura vegetal e ocorrência de nuvens enquanto as 3 bandas no termal são usadas para avaliar a distribuição de temperatura sobre o mar e sobre a terra incluindo-se detecção de focos de calor. Os dados do sensor MODIS serão utilizados no presente estudo na validação dos mapas de susceptibilidade a ocorrência de incêndio no
Parque Estadual da Serra da Concórdia.

O sítio do INPE na internet disponibiliza vasta literatura técnica sobre as observações feitas por satélites, fica, portanto, claro que os dados disponibilizados não devem ser tratados de forma absoluta nem transpostos para situações que fujam de suas limitações.

Para elaboração dos Mapas de Susceptibilidade à Ocorrência de Incêndio da área do Parque Estadual da Serra da Concórdia foi adotado o software Arc Gis 9.2 da ESRI, conforme pode se observar uma tela do software na Figura 1, módulos ArcCatalog, ArcInfo e ArcMap, onde é apresentado o Modelo Digital de Elevação do Parque e os focos de calor nos destaques em amarelo com um triângulo vermelho internamente, detectados no estudo.

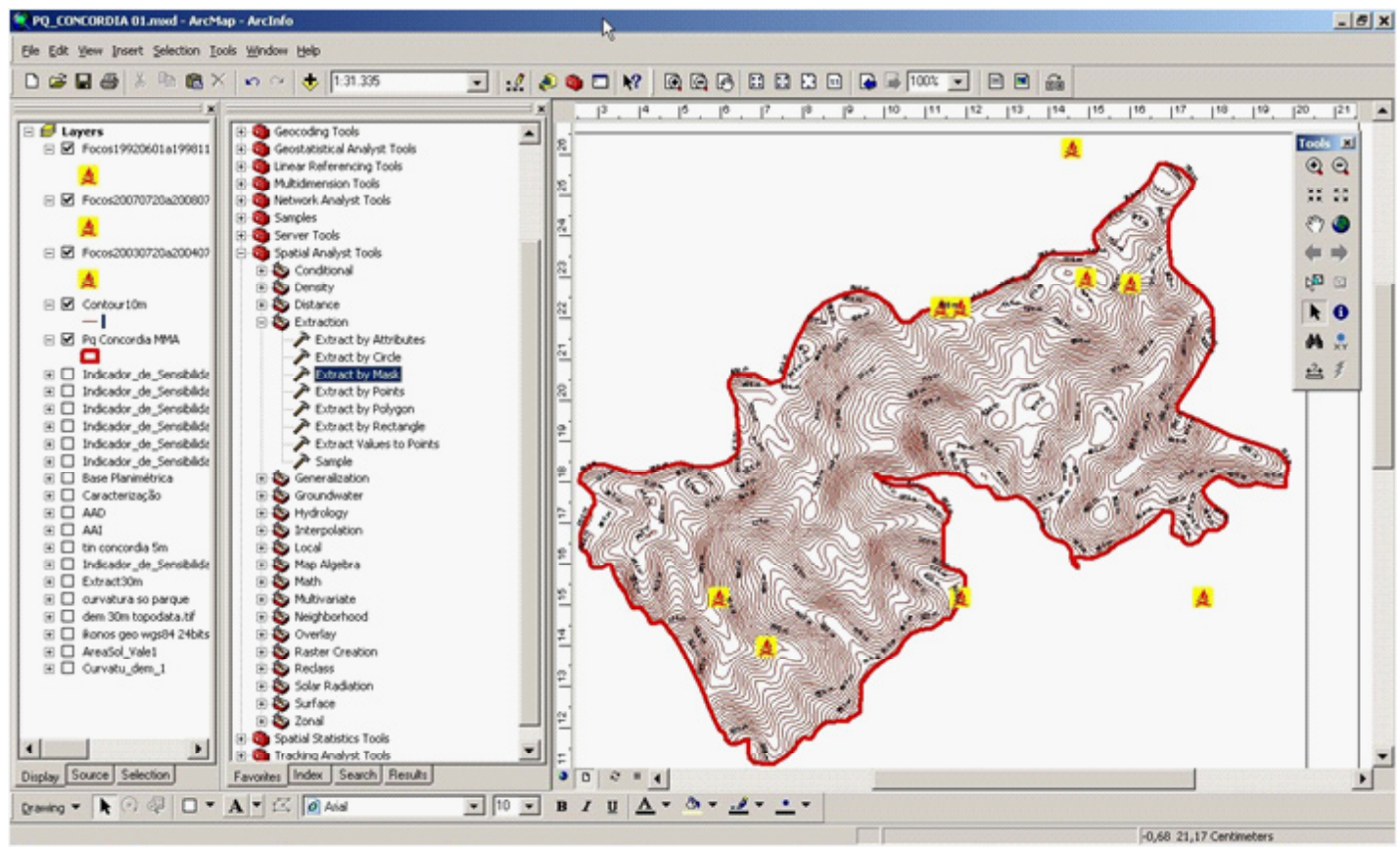

Figura 1. Elaboração dos Mapas de Susceptibilidade à Ocorrência de Incêndio no software ArcGis 9.2.

Para este trabalho utilizou-se de um MDE (Modelo Digital de Elevação) folha 22_45, elaborado a partir da SRTM (Shuttle Radar TopographicMission) no formato GRID, refinado de uma resolução original de 3 arc-seg $(\sim 90 \mathrm{~m})$ para 1 arc-seg $(\sim 30 \mathrm{~m})$, contendo a base de dados georreferenciada e compatível para suprir mapeamentos em escala de até 1:100000 (DGI-INPE 2009).

Como a disponibilização dos mapeamentos utilizados eram oriundos de diversas fontes, fez-se necessária a padronização, através de reprojeção, da representação cartográfica para um único sistema de coordenadas. Optou-se pelo Sistema de Coordenadas Geográficas, com Datum horizontal WGS84, já que a maioria da base cartográfica obtida estava com estas características. Para tanto foi utilizado o software ArcGisem seu módulo ArcCatalog.

Em seguida, já com a base planimétrica ajustada, criou-se um shape de delimitação da área de estudo sobre a imagem original do Ikonos, a fim de maximizar o entorno do Parque Estadual da Serra da Concórdia. Esse shape foi usado no ArcMap em Spacial Analyst Tools $>$ Extration $>$ ExtractbyMask, como janela de recorte da área de estudo para todos os demais temas obtidos.

Para delimitação da área de estudo (criação do shape), inicialmente foi consultado o decreto estadual n. 32.577 de 30 de Dezembro de 2002, que criou o Parque Estadual da Serra da Concórdia, pois no decreto encontram-se os pontos cotados em coordenadas lat- 
long que delimitam sua área. A partir do software Global Mapper 10, foi então criado um shape que se mostrou incongruente devido a incorreções contidas no decreto.

Um shape de delimitação do parque foi então obtido junto ao banco de dados do MMA (Ministério do Meio Ambiente), assim como uma imagem do satélite Ikonos (resolução de $1 \mathrm{~m}$ ) de março de 2007, que foi gentilmente cedida pela Dra. Maria Lucila Chicarino Varajão Spolidoro, ligada à administração do parque. Outros shapes como os de delimitação territorial do estado e municípios foram obtidos junto a base de dados do IBAMA (Instituto Brasileiro de Meio Ambiente).

O mapa de Uso do Solo e Cobertura Vegetal obtido a partir da base AVALIAÇÃO AMBIENTAL
INTEGRADA (AAI-EPE-2009) foi utilizado como subsídio para o Mapa de Combustibilidade em conjunto com os Mapas de Radiação Solar, Forma e de Orientação das Encostas, que geraram os Mapas de Susceptibilidade à ocorrência dos incêndios no Parque Estadual da Serra da Concórdia.

Para tornar possível a validação do método, foram obtidos os dados sobre focos de calor no período de 1998 a 2009, disponibilizados pelo INPE.

A Figura 2 ilustra de forma sucinta a metodologia aplicada neste estudo e consequentemente, realização deste trabalho.

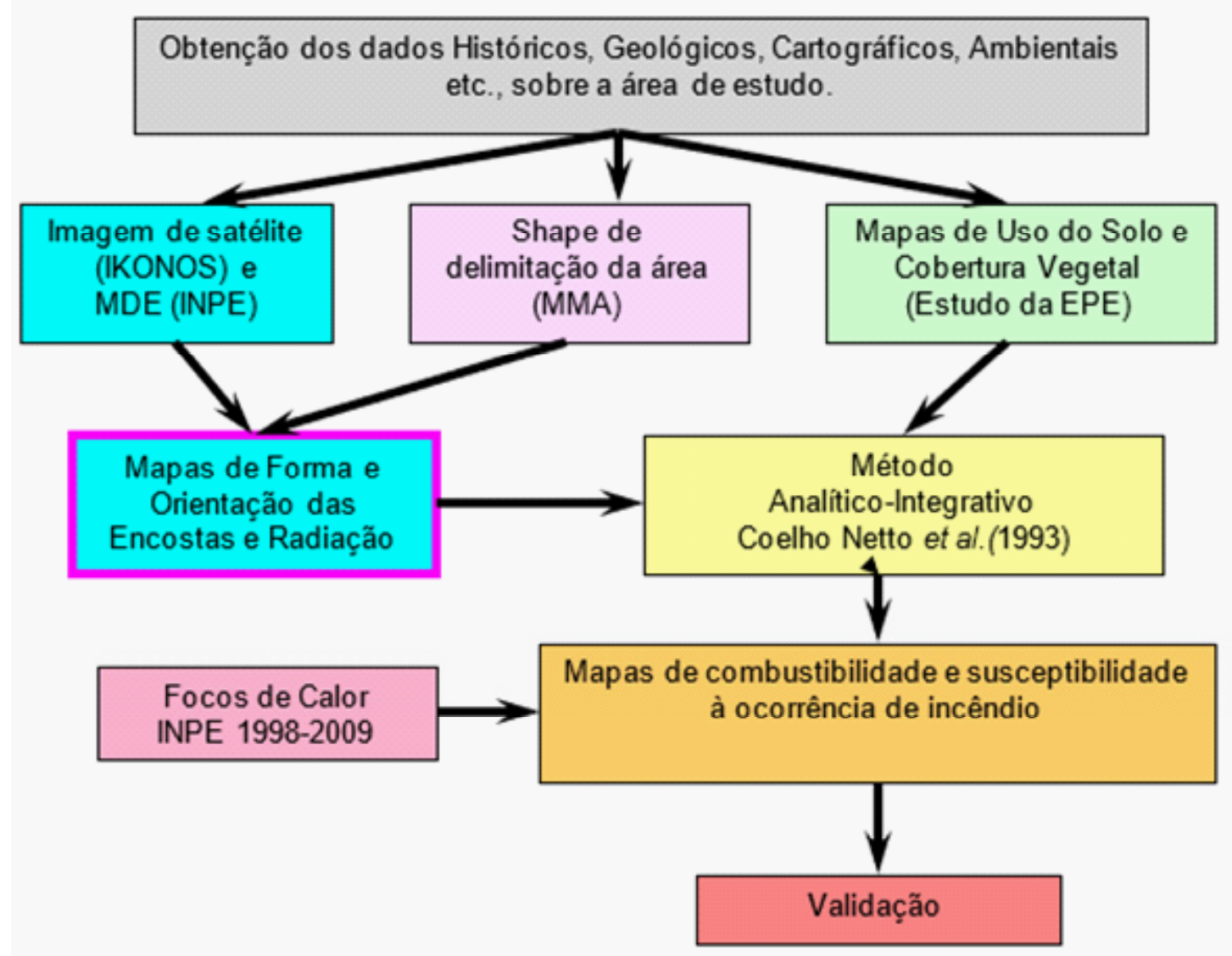

Figura 2. Diagrama do desenvolvimento da Metodologia.

\section{Avaliação de risco e área de risco}

Tratando-se de um modelo de risco, embora neste estudo não se desenvolva na totalidade, é necessário definir todos os conceitos associados a ele, procurando padronizar as ideias que se pretendem transmitir sempre que se aplicam termos como susceptibilidade e risco, entre outros.

De acordo com Castro (2009), a palavra "risco" é utilizada de forma indiscriminada para referir situações de dano potencial e probabilidades de ocorrência. E também se utiliza o termo "risco" para transmitir a noção de iminência de ocorrência de algum fenômeno, quanto a seguir se utiliza a mesma palavra para referir 
perdas, sejam financeiras, materiais ou pessoais.

Castro (2009) define como "ÁREA DE RISCO" a área onde existe a possibilidade de ocorrência de eventos adversos e "AVALIAÇÃO DE RISCO" a Metodologia que permite identificar uma ameaça, caracterizar e estimar sua importância, com a finalidade de definir alternativas de gestão do processo.

Segundo Bachmann e Allgöwer (1999), risco de incêndio florestal define-se como a probabilidade de que um incêndio florestal ocorra num local específico, sobdeterminadas circunstâncias, e as suas consequências esperadas, caracterizadas pelos impactos nos objetos atingidos. Esta definição de Bachmann e Allgöwer cumpre o objetivo de cobrir todas as componentes do modelo de risco,conforme a Figura 3, e é a definição adotada neste trabalho para caracterizar risco de incêndio florestal.

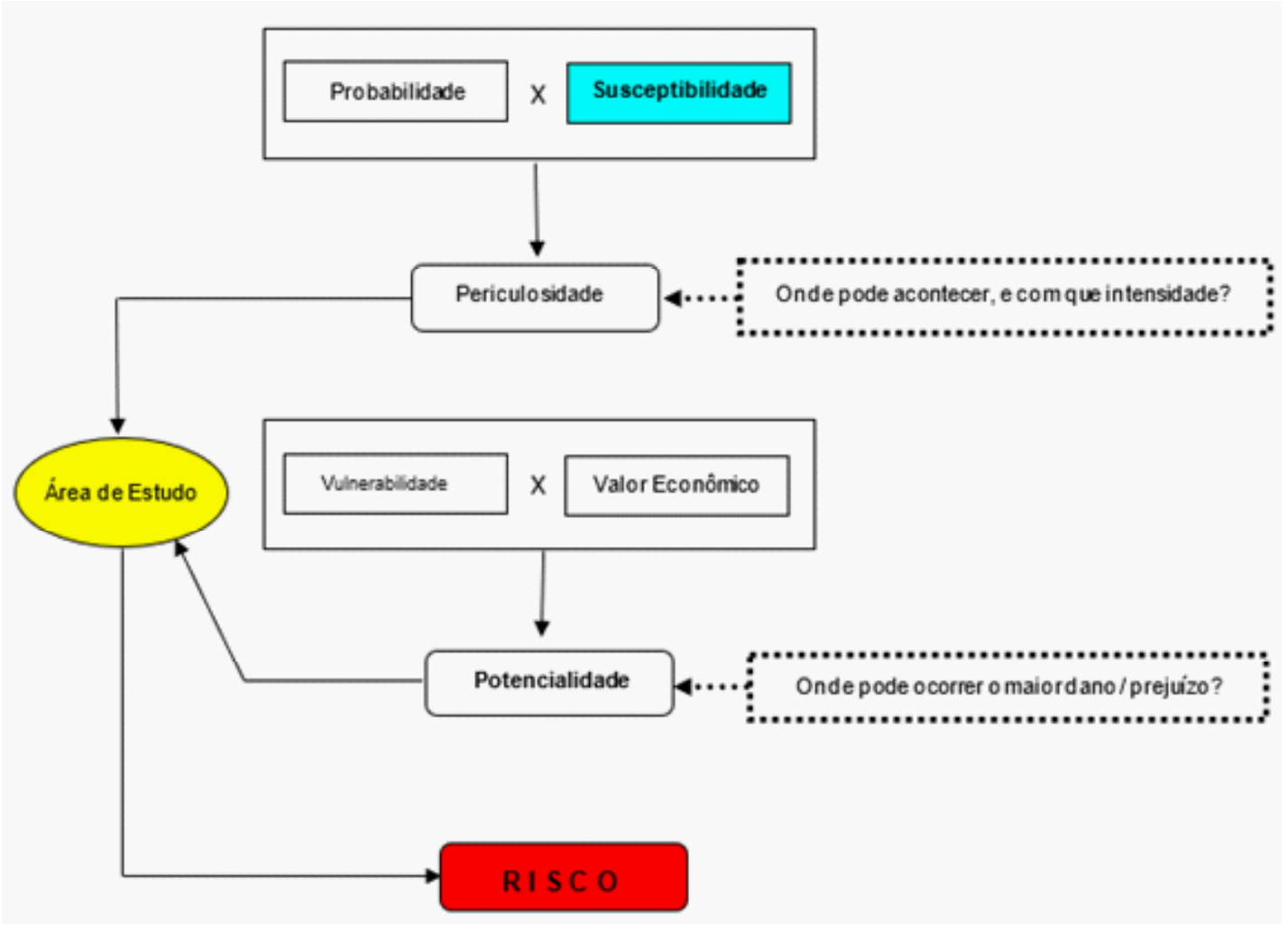

Figura 3. Componentes do modelo de risco.

\section{Probabilidade e susceptibilidade}

A probabilidade expressa a verossimilhança de que um determinado evento ocorra e, deste modo, pode entender-se comoum indicador daincerteza da ocorrência desse evento. Numa abordagem clássica, entende-se que todos os eventos, não estando condicionados a existência própria de outros, têm a mesma possibilidade de ocorrer e, portanto, uma probabilidade igual.

Em probabilidades condicionadas, entende-se que um determinado evento tem uma dada probabilidade de ocorrer, condicionada à probabilidade de que um evento anterior tenha ocorrido. (Reis et al., 2003)

Para Verde e Zêzere (2007) a susceptibilidade expressa a propensão de uma dada área ou unidade territorial para ser afetada pelo fenômeno estudado, avaliada a partir das propriedades que lhe são intrínsecas. Uma unidade territorial pode ser mais ou menos susceptível conforme seja mais afetada ou potencie a ocorrência e desenvolvimento do fenômeno. No caso dos incêndios florestais, uma determinada área pode ser tanto mais susceptível quanto melhor permitir a deflagração e/ou a progressão do incêndio. 


\section{Incêndio Florestal}

Segundo a definição de Ramos (1995), incêndio florestal é todo fogo sem controle que incide sobre qualquer forma de vegetação podendo ter sido provocado pelo homem (intencional ou negligência) ou por fonte natural (raio).

\section{Estudo decaso: mapeamento geoecológico da susceptibilidade à ocorrência de incêndios bo Parque Estadual da Serra da Concórdia - Valença RJ}

O estudo foi desenvolvido no Parque Estadual da Serra da Concórdia com área de 804,41 ha e instituído pelo Decreto Estadual $\mathrm{n}^{\mathrm{o}} 32.577$ de 30/12/2002. Localizado no município de Valença, Estado do Rio de Janeiro, na margem esquerda do Rio Paraíba do Sul,conforme se observa na Figura 4, no curso médio da bacia hidrográfica, entre as coordenadas geográficas $22^{\circ} 18^{\prime}$ a $22^{\circ} 24^{\prime}$ de latitude sul e $43^{\circ} 40^{\prime}$ a $43^{\circ} 47^{\prime}$ de longitude oeste.

A Serra da Concórdia onde está localizado o Parque Estadual da Serra da Concórdia, segundo RADAMBRASIL (1983), conforme Figura 5, possui relevo fortemente ondulado com posicionamento altimétrico entre 350 a 1020 metros, tendo na sua base os modelados de dissecação homogênea com orientação preferencial de suas vertentes na direção sudeste.

A área se enquadra nas feições características do Planalto do Sudeste do Brasil, onde segundo Moura et al. (1992) são comuns as cabeceiras de drenagem em anfiteatro, onde se desenvolvem os "complexos de rampa" propiciando um intenso processo erosivo com a formação de voçorocas a partir dos canais fluviais

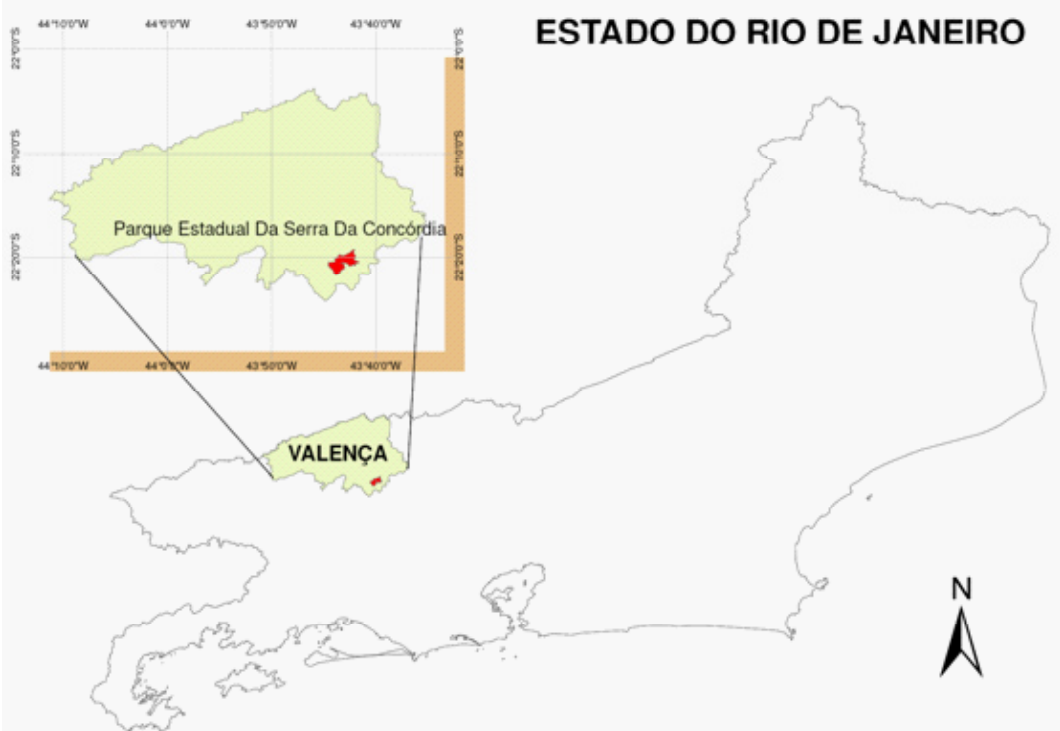

Figura 4. Localização do Parque Estadual da Serra da Concórdia.

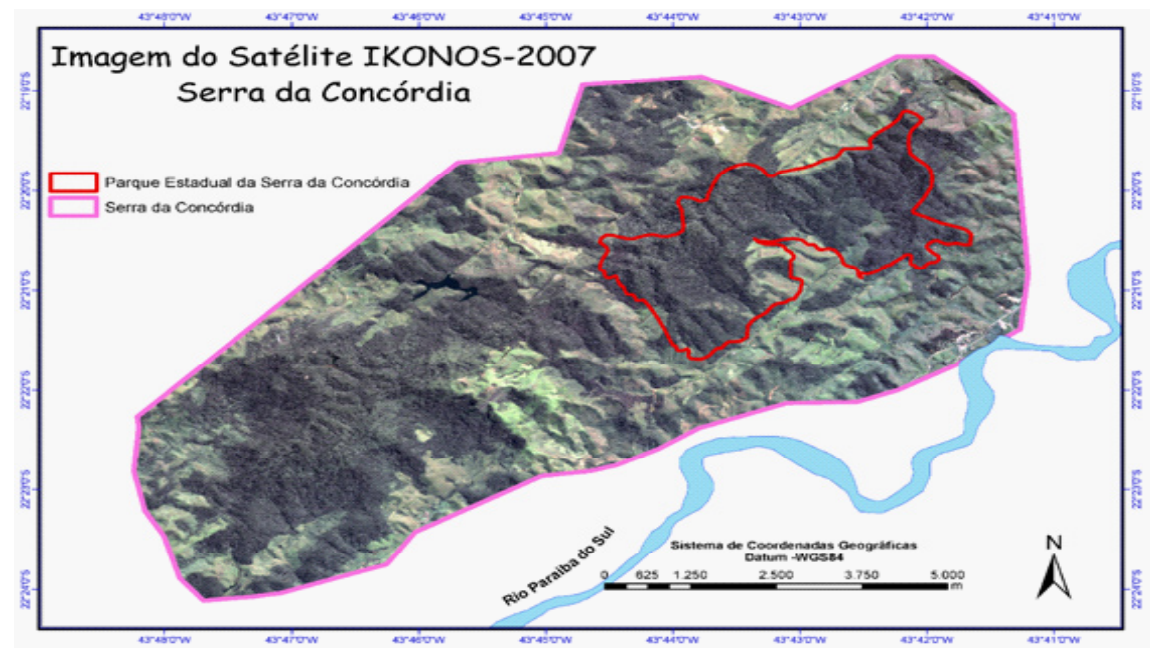

Figura 5. Delimitação da área de estudo 
principais e secundários em direção a antigas linhas de drenagem acarretando seu entulhamento. Este processo tem se desdobrado em uma taxa de sedimentação e assoreamento acelerado dos canais fluviais, certamente induzida ou /e intensificada pela atividade antrópica.

\section{Vegetação}

O Parque Estadual da Serra da Concórdia como todo o Vale do Paraíba do Sul eracoberto por formações florestais que perduraram sem significativas alterações até oinício do século XIX,segundo Golfari e Moosmayer (1980), tendo sido progressivamente substituídas por plantações de café e posteriormente por pastagens.

As áreas abandonadas foram sendo ocupadas por florestas secundárias que atualmente se encontram em diferentes estágios sucessionais. (Spolidoro, 2001)

\section{Levantamento de dados}

O presente estudo utilizou-se de um MDE (Modelo Digital de Elevação) folha 22_45,elaborado a partir da SRTM (Shuttle Radar TopographicMission) no formato GRID,refinado de uma resolução original de 3 arc-seg $(\sim 90 \mathrm{~m})$ para 1 arc-seg $(\sim 30 \mathrm{~m})$, contendo a base de dados georreferenciada e compatível para suprir mapeamentos em escala de até 1:100000. (DGI-INPE 2009)

Para delimitação da área de estudo (criação do shape), inicialmente foi consultado odecreto estadual n. 32.577 de 30 de Dezembro de 2002, que criou o ParqueEstadual da Serra da Concórdia, pois no decreto encontram-se os pontos cotadosem coordenadas latlong que delimitam sua área. A partir do software Global Mapper10, foi então criado um shape que se mostrou incongruente devido a incorreçõescontidas no decreto.

Um shape de delimitação do parque foi então obtido junto ao banco de dados do MMA (Ministério do Meio Ambiente), assim como uma imagem do satélite Ikonos (resolução de $1 \mathrm{~m}$ ) de março de 2007, que foi gentilmente cedida pela Dra. MariaLucila Chicarino Varajão Spolidoro, ligada à administração do parque. Outros shapes como os de delimitação territorial do estado e municípios foram obtidos junto a basede dados do IBAMA (Instituto Brasileiro de Meio Ambiente).

Mapas de Ocupação do Solo, Geomorfologia, Geologia, Hidrografia etc. foramadquiridos a partir da AVALIAÇÃO AMBIENTAL INTEGRADA (AAI) "dosAproveitamentos Hidrelétricos da Bacia do Rio Paraíba do Sul", relatórioelaborado pela EPE (Empresa de Pesquisa Energética - 2007).

Por fim, para tornar possível a validação do método, foram obtidos os dados sobrefocos de calor no período de 1998 a 2009, disponibilizados pelo INPE.

\section{Padronização e ajuste da base de dados}

Como a disponibilização dos mapeamentos utilizados eram oriundos dediversas fontes, fez-se necessária a padronização, através de reprojeção, darepresentação cartográficapara um único sistema de coordenadas, optou-se peloProjeção Geográfica, com Datum horizontal WGS84, já que a maioria da basecartográfica obtida estava com estascaracterísticas. Para tanto foi utilizado o software ArcGisem seu módulo ArcCatalog.

Já com a base planimétrica ajustada, criouse um shape de delimitação da área de estudo sobre a imagem original do Ikonos, a fim de maximizar o entorno do Parque Estadual da Serra da Concórdia. Esse shape foi usado no ArcMap em Spacial Analyst Tools $>$ Extration $>$ ExtractbyMask, como janela de recorte da área de estudo para todos os demais temas obtidos. Na etapa seguinte, aplicou-se a parte do DEM obtida o comando Fill do módulo Hydrology, a fim de corrigir possíveis depressões falsas comuns aos MDEs.

\section{Elaboração dos mapas temáticos}

O uso direto da elevação como fator analítico contido nos MDEs tem papel preponderante para conhecimento do relevo, bem como análises da hidrologia superficial. As características fisiográficas que determinam os canais de drenagem,são, portanto, um instrumento poderoso para obtenção das diversas informaçõesligadas ao regime hidrológico de uma região. Conforme observa-se na Figura 6.

O mapa de uso e cobertura do solo obtido a partir da AVALIAÇÃOAMBIENTAL INTEGRADA (AAIEPE-2009) apresenta-se na Figura 7.

A Figura 8 representa a reclassificação do Mapa de Uso e Cobertura do Soloutilizando o método integrativo para a obtenção das classes que compõem o mapa de combustibilidade.

Para o mapa da Figura 7 foi utilizado como subsídio para o mapa de combustibilidade em conjunto com o mapa de radiação solar e forma de encosta, que geraram o mapa de susceptibilidade à ocorrência dos incêndios no Parque Estadual da Serra da Concórdia. Conforme a figura 9.

Nas Figuras 9 e 10 são apresentados os dados de Focos de Calor confrontados com susceptibilidades em função da radiação solar total e da orientação das encostas.

\section{Análise dos mapas e validação}

Os resultados obtidos revelaram que a metodologia do mapeamento geoecológico da 


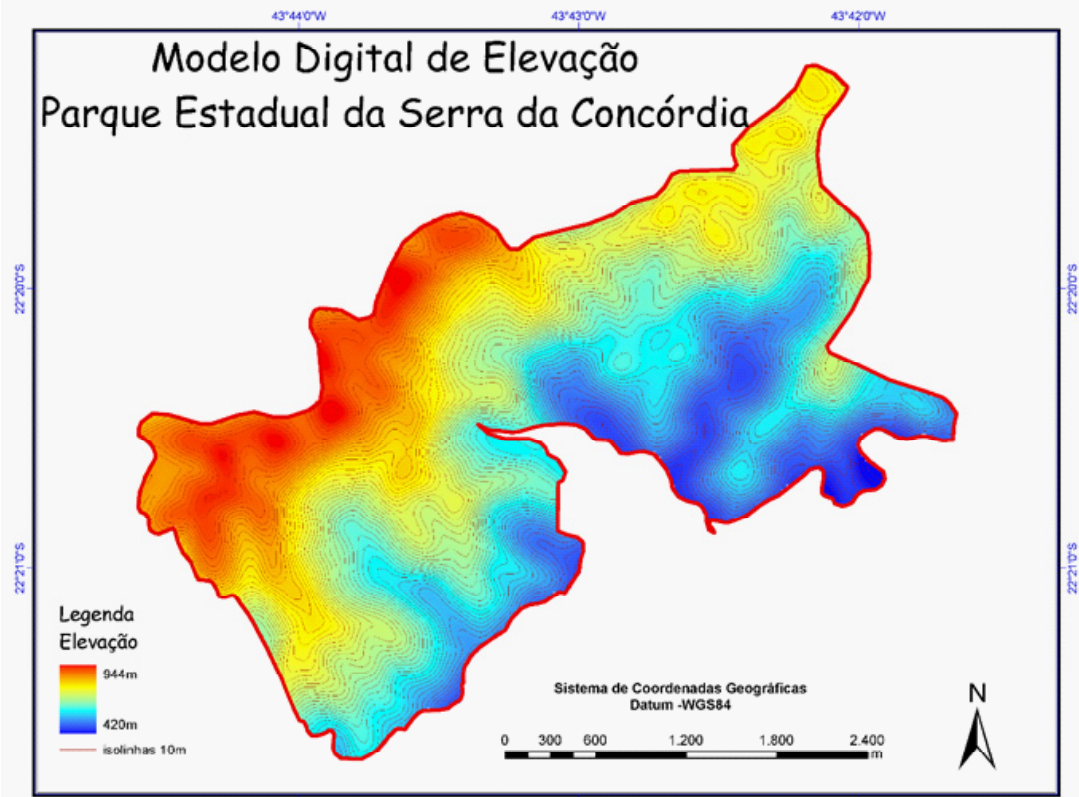

Figura 6. Modelo Digital de Elevação do Parque Estadual da Servra da Concórdia. Fonte: Do Autor, 2011

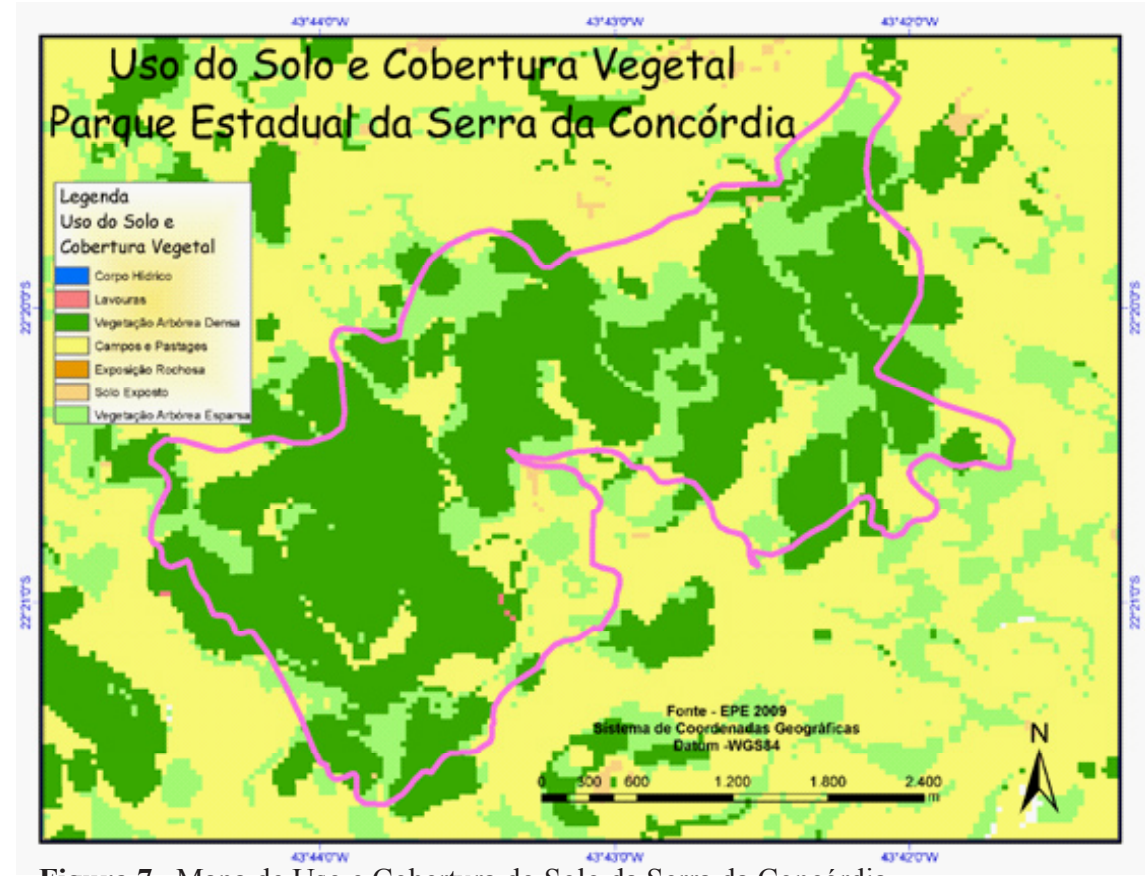

Figura 7. Mapa de Uso e Cobertura do Solo da Serra da Concórdia.

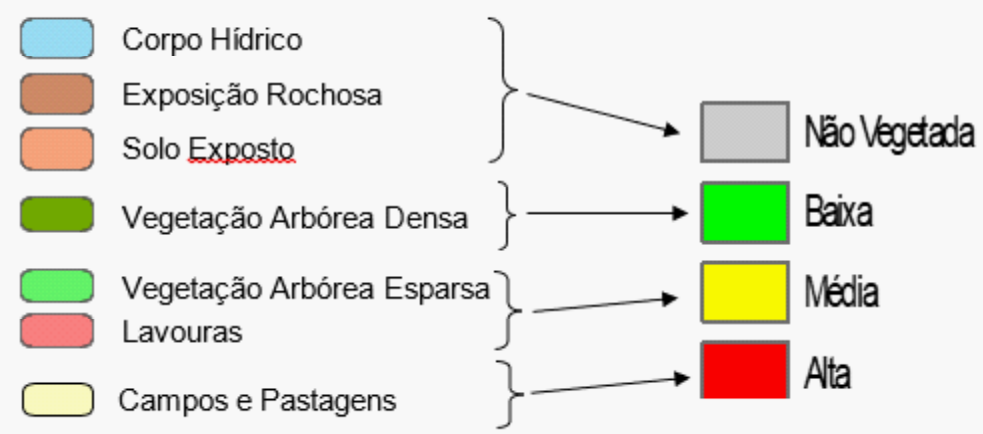

Figura 8. Representação do Método Integrativo. 


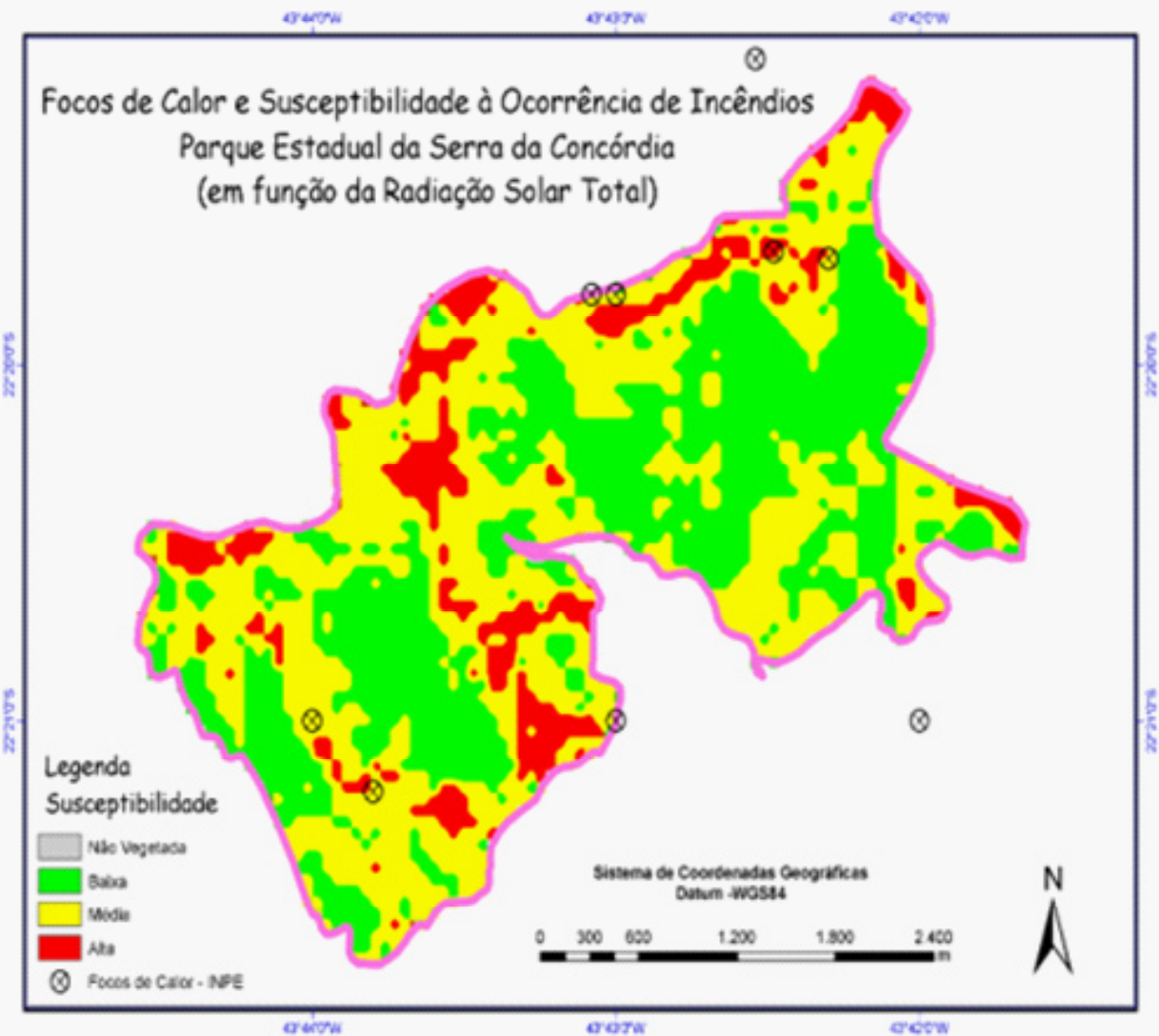

Figura 9. Focos de Calor confrontados com susceptibilidades em função da radiação solar (I).

Fonte: Do Autor, 2011

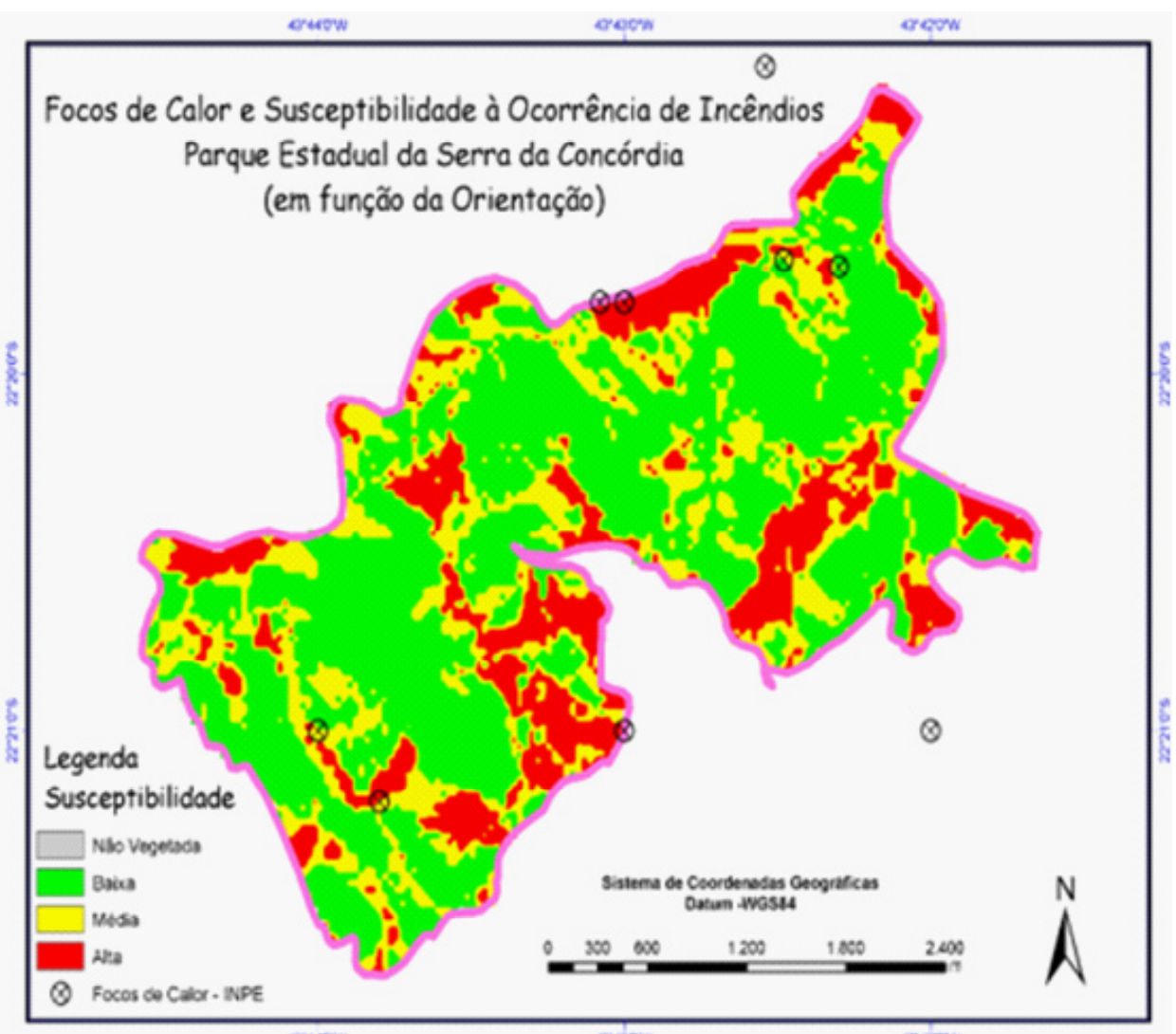

Figura 10. Focos de Calor confrontados com susceptibilidades em função da orientação das encostas (II). 
susceptibilidade à ocorrência de incêndios do Parque Estadual da Serra da Concórdia pode ser validada por meio dos dados que foram obtidos da DGI -INPE com relativa precisão.

Mesmo de forma isolada, quando os mapas temáticos são confrontados com os focos de calor detectados pelo INPE, já é possível observar com grande aproximação que há coincidência entre a predição e os focos ocorridos, conforme Figura 11.

No período a que se refere a identificação dos focos de calor, que vai de 1998 a 2009, foram contabilizados 7 ocorrências dentro da área do parque. Considerandoas comparações efetuadas entre os mapas produzidos e os focos de calor, pode-se afirmar que a metodologia apresentada neste trabalho mostrou-se eficiente para representar a susceptibilidade à ocorrência de incêndio florestal no Parque Estadualda Serra da Concórdia, pois é possível verificar que os focos de calor encontramsedentro dos polígonos de maior pré-disposição há ocorrência de incêndios.

As Figuras 12 e 13 representam as estatísticas obtidas a partir das Figuras 9 (Focos de Calor confrontados com susceptibilidades em função da radiação solar) e 10 (Focos de Calor confrontados com susceptibilidades em função da orientação das encostas).

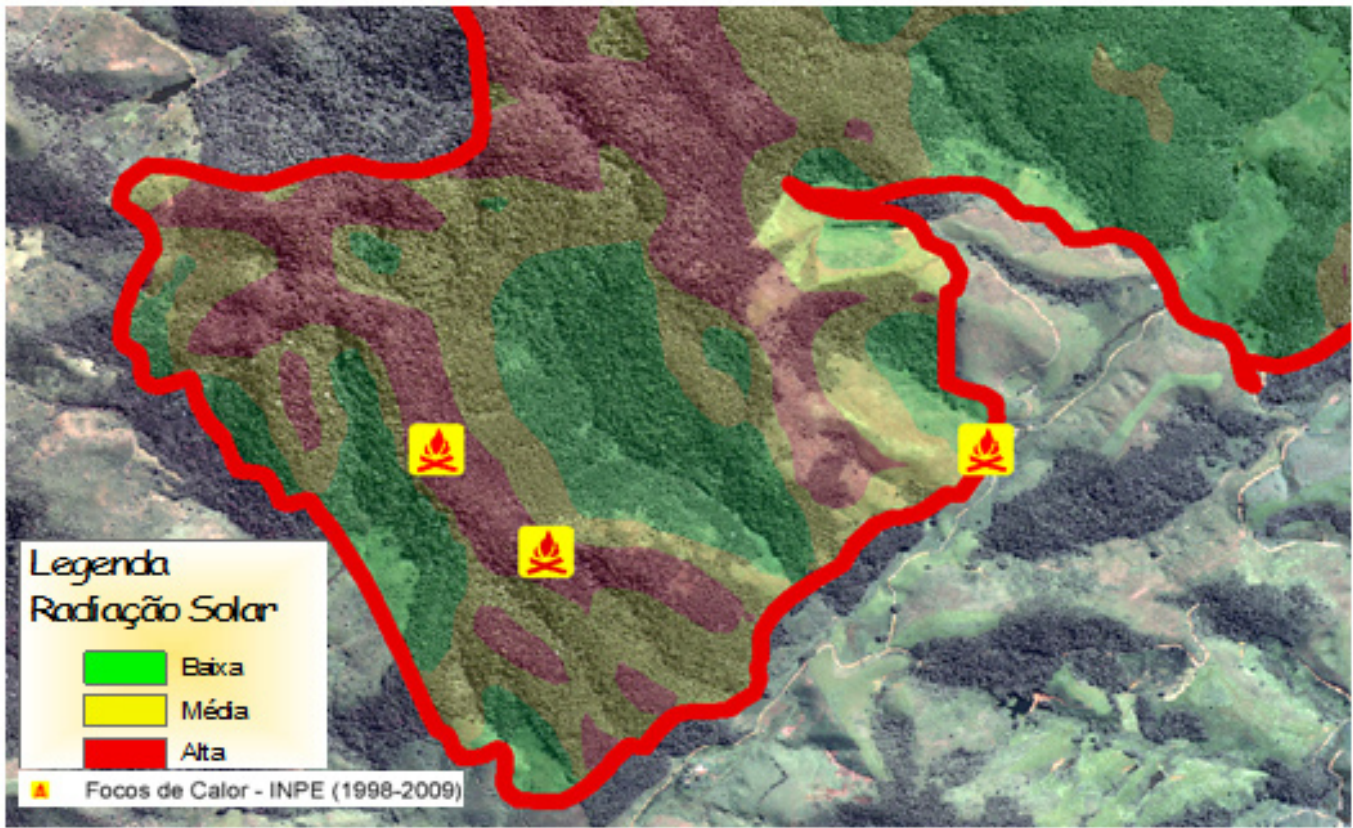

Figura 11. Imagem do IKONOS com sobreposição ao Mapa de Radiação Solar Total indicando os Focos de Calor detectados sobre a área de alta insolação, mostrando a propensão e a ocorrência de incêndios na área indicada.

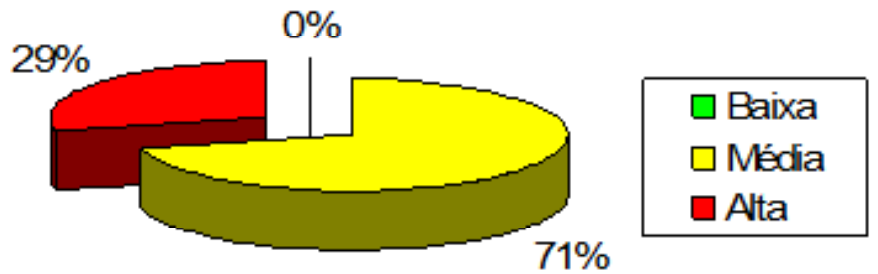

Figura 12. Percentual dos focos de calor detectados em relação à área afetada no Mapa da Susceptibilidade em função da radiação solar (I). 


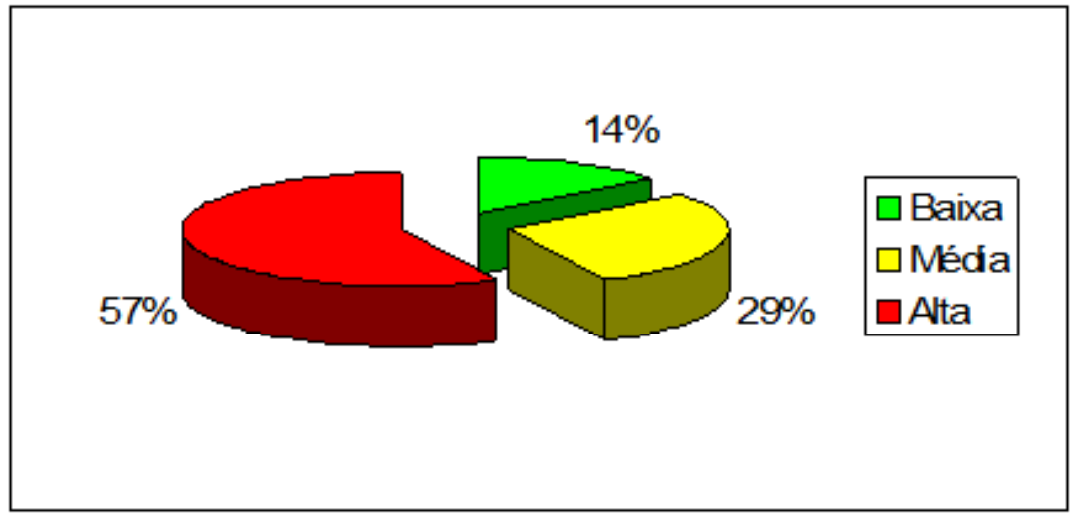

Figura 13. Percentual dos focos de calor detectados em relação à área afetada no Mapa da Susceptibilidade em função da orientação das encostas (II).

Fonte: Do Autor, 2011

\section{Resultados e discussão}

Os mapas gerados a partir dos Modelos Digitais de Elevação possibilitam inúmeras avaliações que são importantes para este estudo, como o Mapa de Orientação de Encosta, Forma de Encosta e Radiação Solar Anual. A seguir são apresentados detalhamentos dos resultados e análises dos mapas gerados a partir do MDE.

A orientação das encostas é a principal variável que regula a susceptibilidade à ocorrência de queimadas, à medida que controla decisivamente o teor de umidade do solo. Esta afirmação foi baseada nos estudos conduzidos por Oliveira et al. (1995) que verificaram a ocorrência quase exclusiva de queimadas nas encostas do maciço da Tijuca voltadas para o norte.

Ainda segundo Oliveira et al. (1995), as encostas voltadas para o sul possuem vegetação em média $41,9 \%$ mais úmida que as voltadas para o norte. Além disso, ainda afirmam que a perda desta umidade também se dá muito mais rápido nas encostas voltadas para o norte, pois as voltadas para o sul retém a umidade 1,6 vezes mais que as voltadas para o norte. Consequentemente a umidade do solo se comporta da mesma maneira apenas variando de acordo com o tipo de cobertura vegetal a que está associado.

Existem variações no caráter geomorfológico que individualizam dentro das encostas áreas mais ou menos propícias à ocorrência de queimadas. Estas são segmentos geométricos que se apresentam sob três formas principais: côncavos, convexos e retilíneos. As formas côncavas se caracterizam como zonas de convergências de fluxo e consequentemente de maior concentração de umidade, ao passo que as convexas e retilíneas (em encostas) condicionam a formação de zonas de divergências de água e baixa umidade.

Portanto, ao aplicar-se o método integrativo em um mapa de orientação com o de formas de encostas, podem-se definir dentro das encostas voltadas para o norte e sul segmentos de maior ou menor propensão à ocorrência de queimadas.

É possível classificar, utilizando o método analítico-integrativo, as áreas de susceptibilidade de ocorrência de incêndios em alta susceptibilidade, média susceptibilidade e baixa susceptibilidade, conforme mostrado nos Quadros 1 e 2.

Dentre os produtos que podem ser obtidos do MDE, está o Mapa do Total de Radiação Solar que atinge uma determinada região em um período de tempo. Desse mapa pode-se extrair inclusive o detalhamento da quantidade de energia por unidade de área em W/ $\mathrm{m}^{2}$. Portanto a análise da orientação das encostas, forma das encostas, associada ao mapa do total de radiação solar é capaz de revelar características de umidade ou ressecamento da cobertura vegetal.

\section{Conclusão}

O presente estudo mostrou que a partir de dados que são disponibilizados de forma gratuita e diária na internet, é possível elaborar um conjunto de ferramentas de monitoramento e prevenção à ocorrência de incêndios florestais. Assim, torna-se possível prevenir e antecipar as ações de combate e minimizar as perdas caso ocorra um incêndio. E ainda foi possível verificar que a metodologia empregada para produção dos Mapas de Susceptibilidade apresentou elevados índices de predição. No primeiro caso, o mapa de susceptibilidade (1), Figura 9, as áreas afetadas, classificadas como de média e alta susceptibilidade à ocorrência de incêndios, os percentuais de coincidência foram respectivamente iguais a $71 \%$ e $29 \%$. Já no segundo mapa, o de susceptibilidade (2), Figura 10, os índices apontam valores de alta e média susceptibilidade, respectivamente como: $57 \%$ e $29 \%$.

No entanto é necessário ressaltar que alguns mapas, como os de Uso do Solo e Cobertura Vegetal, devem ser atualizados periodicamente, pois as condições 
Quadro 1. Método analítico-integrativo para composição das classes de susceptibilidade.

\begin{tabular}{|c|c|c|}
\hline Radiação & Forma & Combustibilidade \\
\hline Alta & Côncavo & Área não Vegetada \\
\hline Alta & Convexo & Área não Vegetada \\
\hline Alta & Côncavo & Alta \\
\hline Alta & Convexo & Alta \\
\hline Alta & Côncavo & Média \\
\hline Alta & Convexo & Média \\
\hline Alta & Côncavo & Baixa \\
\hline Alta & Convexo & Baixa \\
\hline Média & Côncavo & Área não Vegetada \\
\hline Média & Convexo & Área não Vegetada \\
\hline Média & Côncavo & Alta \\
\hline Média & Convexo & Alta \\
\hline Média & Côncavo & Média \\
\hline Média & Convexo & Média \\
\hline Média & Côncavo & Baixa \\
\hline Média & Convexo & Baixa \\
\hline Baixa & Côncavo & Área não Vegetada \\
\hline Baixa & Convexo & Área não Vegetada \\
\hline Baixa & Côncavo & Alta \\
\hline Baixa & Convexo & Alta \\
\hline Baixa & Côncavo & Média \\
\hline Baixa & Convexo & Média \\
\hline Baixa & Côncavo & Baixa \\
\hline Baixa & Convexo & Baixa \\
\hline & & \\
\hline
\end{tabular}

\begin{tabular}{|c|}
\hline Susceptibilidade (1) \\
\hline Área não Vegetada \\
\hline Área não Vegetada \\
\hline Alta \\
\hline Alta \\
\hline Alta \\
\hline Média \\
\hline Média \\
\hline Alta \\
\hline Área não Vegetada \\
\hline Área não Vegetada \\
\hline Média \\
\hline Alta \\
\hline Média \\
\hline Média \\
\hline Baixa \\
\hline Média \\
\hline Área não Vegetada \\
\hline Área não Vegetada \\
\hline Baixa \\
\hline Média \\
\hline Baixa \\
\hline Média \\
\hline Baixa \\
\hline Baixa \\
\hline
\end{tabular}

Fonte: Do Autor, 2011 
Quadro 2. Método analítico-integrativo para composição das classes de susceptibilidade.

\begin{tabular}{|c|c|c|}
\hline Orientação & Forma & Combustibilidade \\
\hline Norte & Côncavo & Area năo Vegetada \\
\hline Norte & Convexo & Alta \\
\hline Norte & Côncavo & Média \\
\hline Norte & Convexo & Baixa \\
\hline Norte & Côncavo & Area não Vegetada \\
\hline Norte & Convexo & Alta \\
\hline Norte & Côncavo & Média \\
\hline Norte & Convexo & Baixa \\
\hline Sul & Côncavo & Area não Vegetada \\
\hline Sul & Convexo & Alta \\
\hline Sul & Côncavo & Média \\
\hline Sul & Convexo & Baixa \\
\hline Sul & Côncavo & Area năo Vegetada \\
\hline Sul & Convexo & Alta \\
\hline Sul & Côncavo & Média \\
\hline Sul & Convexo & Baixa \\
\hline & & \\
\hline
\end{tabular}

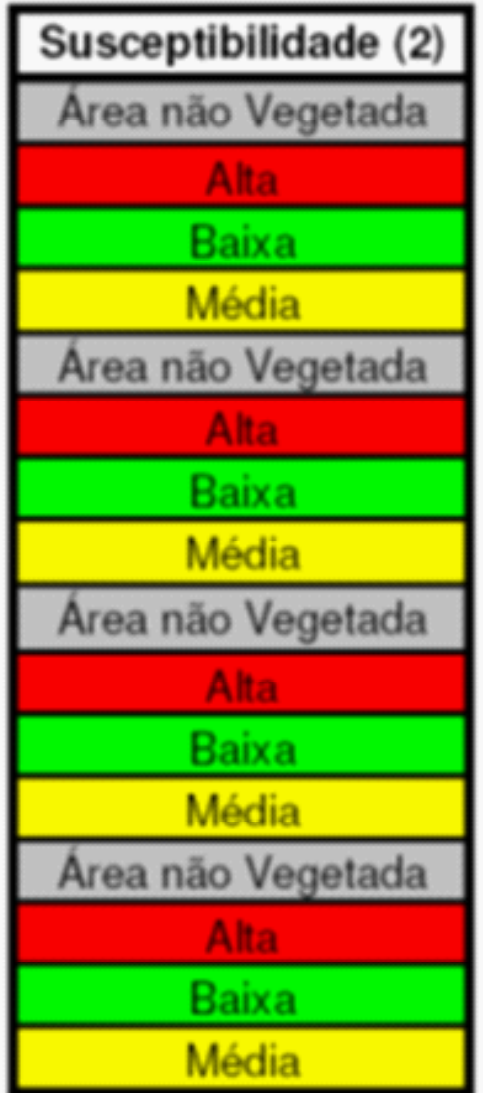

Fonte: Do Autor, 2011 ambientais estão em constante mudança, o que pode alterar as condições de susceptibilidade com o passar do tempo.

Entre as restrições deste estudo, está a detecção das fontes de calor por imagens de satélite obtidas do INPE. Os sensores a bordo dos satélites possuem limitações que devem ser identificadasde maneira a evitar generalizações que podem comprometer o monitoramento e a elaboração dos mapas de avaliação de uma determinada região.

\section{Referências Bibliográficas}

Bachman, A. Allgower, B. A,. (2001). Consistent Wildland Fire Risk Terminology is Needed, Fire Management Today (4 ed., Vol. 61, pág. 2833). Zurich, Fall.

Câmara, I. de G. (1991). Plano de ação para a mata atlântica. São Paulo: Fundação SOS Mata Atlântica, 152p.

Castro, et al. (2005) Riscos Ambientais e Geografia: Conceituações, Abordagens e Escalas. Environmental RisksandGeography: Conceptualizations, Approaches andScales. Anuário do Instituto de Geociências - UFRJ. Vol. 28-2 p. 11-30.

Coelho Netto, A. L.; Avelar, A. S.; Fernandes, M. C. \& Lacerda, W. 2007. A Landslide Susceptibility in a Mountainous Geoecosystem, Tijuca Massif, Rio de Janeiro: The Role of Morphometric Subdivision of the Terrain. In: GEOMORPHOLOGY (Amsterdam), 87:120 - 131.

Embrapa, CNPS. (2006). Sistema Brasileiro de Classificação de Solos (2a ed., Vol., pág. 1-412). Brasilia, Distrito Federal: EMBRAPA.
EPE. (2007, 08). Avaliação Ambiental Integrada dos Aproveitamentos Hidrelétricos da Bacia do Rio Paraíba do Sul. Avaliação Ambiental Integrada. Retirado 11, 2018, de http://www.epe.gov.br/pt/publicacoes-dados-abertos/ publicacoes/avaliacao-ambiental-integrada-aai

ESRI (2002) - Using ArcGIS - Spatial Analyst. ESRI, USA.

Fernandes, M. C. (1998). Geoecologia do maciço da Tijuca-RJ: uma abordagem geohidroecológica. In (pp. 141). Rio de Janeiro.

Golfari, L.; Moosmayer, H. (1980). Manual de reflorestamento do Estado do Rio de Janeiro (1 ed., Vol., pág. 1-382). Rio de Janeiro, Rio de Janeiro: EMBRAPA.

Ministério da Ciência, Tecnologia, Inovações e Comunicações. DGIINPE(2009, 06). Geração de Imagens. Catalogo. Retirado 03, 2018, de http:// www.dgi.inpe.br/CDSR/

Ministério da Ciência, Tecnologia, Inovações e Comunicações. (2011, 06). Queimadas. Perguntas Frequentes. Retirado 03, 2018, de http://www.inpe. br/faq/

Jusbrasil. (2002, 12). Decreto $\mathrm{n}^{\mathrm{o}} 32.577$ de 30 de dezembro de 2002. Legislação. Retirado 06, 2018, de https://gov-rj.jusbrasil.com.br/ legislacao/140826/decreto-32577-02

Ministério da Ciência, Tecnologia, Inovações e Comunicações. CPTECINPE. (2011, 01). Sistemas de Monitoramento. Programa Queimadas. Retirado 06, 2018, de http://queimadas.dgi.inpe.br/queimadas/portal

Ministério das Minas e Energia. (1983, 01). Projeto RADAMBRASIL, Geologia, Geomorfologia, Pedologia. RADAM D. Retirado 06, 2018, de http://www.cprm.gov.br/publique/Geologia/Sensoriamento-Remoto-eGeofisica/RADAM-D-628.html

Ministério da Integração Nacional. (2009). Glossário de Defesa Civil Estudos de Riscos e Medicina do DesastreVol, 1(pp. 1-191). Brasília: Ministério da 


\section{Integração Nacional.}

Ministério do Meio Ambiente (2000, 03). Avaliação e Ações Prioritárias para a Conservação da Biodiversidade da Mata Atlântica e Campos Sulinos. Áreas prioritárias - Avaliação - Mata Atlântica e Campos Sulinos. Retirado 08, 2018, de https://www.mma.gov.br/estruturas/sbf_chm_rbbio/_arquivos/ Sumario\%20Mata\%20Atlantica.pdf

Moura, J.R.S, Peixoto, M.N.O, Silva, T.M, \& Mello, C.L. (1992). Mapas de feições geomorfológicas e coberturas sedimentares quaternárias: abordagem para o planejamento ambiental em compartimentos de colinas no Planalto Sudeste do Brasil. In CONGRESSO BRASILEIRO DE GEOLOGIA (pp. 6062). São Paulo: SBG.

Oliveira, R.R, Zau, A.S., Flores, D.F, Viana, M.C., Sodre, D.O., \& Sampaio, P.D. (1995). Significado ecológico da orientação de encostas no maciço da Tijuca, Rio de Janeiro. Oecologia Brasiliensis, 1(1), 523-541.

Ramos, P. (1995). Sistema Nacional de Prevenção e Combate aos Incêndios Florestais. In Forum Nacional Sobre Incêndios Florestais (pp. 29-38). São Paulo: IPEF.

Reis, E., Melo, P., Andrade, R., \&Calapez, T. (2003). Estatística Aplicada (4 ed.). Lisboa: Edições Sílabo.

Setzer, A.; Morelli, F. \& Jesus, S.C. 2010. Queimadas e incêndios na vegetaçãoocorridos no interiordo Parque Nacional da Serra da Canastra, MG, em agosto de 2008. (pp. 1-18) São Paulo. INPE.

Sousa, G.M. (2009). Mapeamento Geoecológico da Potencialidade à Ocorrência de Incêndios no Maciço da Pedra Branca/RJ. (Mestrado). UFRJ.

Spolidoro, M.L.C.V (2001). Composição e estrutura de um trecho de floresta no médio Paraíba do Sul, RJ (Mestrado). UFRRJ.

Verde, J., \& Zêzere, J. (2007). Avaliação da perigosidade de incêndio florestal. In VI Congresso da Geografia Portuguesa (p. 27). Lisboa: Universidade Nova de Lisboa. 